\title{
A Specific Image Processing Code in MatLab to Perform Advanced Nodularity and Nodule Count Analysis of Austempered Ductile Iron Castings
}

\author{
Baris Cetin $^{1}$, Huseyin Kurtuldu ${ }^{2}$, Goksel Durkaya ${ }^{3}$ and Kemal Davut ${ }^{3,4}$ \\ 1. FNSS Defense Systems Co. Inc., Department of Engineering and Research, Ankara, Turkey \\ 2. Baskent University, Dept. of Biomedical Engineering, Ankara, Turkey \\ 3. Atilim University, Dept. of Metallurgical and Materials Engineering, Ankara, Turkey \\ 4. Atilim University, Metal Forming Center of Excellence (MFCE), Ankara, Turkey
}

A combination of high tensile and fatigue strength, good ductility, high toughness and wear resistance is required for most engineering applications. Unfortunately, those properties can be enhanced at cost of each other, so a good combination of those properties cannot be realized easily. In that sense, austempered ductile iron castings (ADI) provide a good alternative in fulfilling these requirements concurrently in an economical way [1]. Those promising combination of mechanical properties can be achieved by producing a very specific microstructure [2]. ADI microstructure is composed of spheroidal graphite particles in an ausferritic matrix [3]. The size, shape, fraction and specifically the nodularity of graphite particles as well as the matrix microstructure influences the mechanical properties.

In this contribution, a specific image processing code to perform advanced nodularity analysis is presented. This nodularity analysis are performed using a newly developed MatLab script, using the micrographs taken by an optical microscope with motorized axes. The ADI sample were raster scanned at 100 fields corresponding to a total scan area of $165 \mathrm{~mm}^{2}$; and optical micrographs at each field were taken under bright field illumination. Figure 1a shows the raster scan pattern to obtain micrographs. Creation of a specific MatLab script was necessary for providing statistically meaningful information in nodularity. The script calculates nodularity in accordance with the ASTM E2567 standard [4]. The graphite nodules are clearly visible in as-polished micrographs and the script is able to detect graphite particles as shown in Figures $1 \mathrm{~b}$ and 1c, respectively.

The results of the raster scan after processing with MatLab script is shown in Figure 2. Figure 2a shows the number of nodular particles per unit area, $2 b$ the average size of graphite nodules and $2 c$ the nodularity by area values. All those figures show significant field-to field variations. The number of graphite nodules vary from 7 to 57 and the size of the nodules from 28 to $57 \mu \mathrm{m}$. The nodularity values vary in the range of 0.8 to 0.64 . Since cooling effects may vary in depth and in the material matrix spatially. This may induce different segregation dynamics due to the variation of local thermodynamic properties [5]. Furthermore, alloying with different materials such as $\mathrm{Ni}, \mathrm{Mn}$ and $\mathrm{Fe}$ may modify compositional behaviour resulting in different segregation dynamics which in turn modifies nodular properties [6]. As a result of those facts the nodularity of the casting may vary remarkably with respect to the position. Figure 2 also indicates spatial dependence of nodularity, number and size of nodule particles; all those parameters are low at the lower part of the scanned area.

The ASTM E2567 standard leaves the minimum number of specimens and minimum number of scanned area to be determined by producer-purchaser agreement. The standard specifies the minimum number of particles (all should meet the size criteria) measured, to determine nodularity, to be 500. For the present analysed material this is equivalent to analysing only 12 to 14 fields. However; results shown in Figure 2 indicates that measuring at least 100 fields gives more representative results. Raster-scanning over a 
larger area not only improves the accuracy and representativeness of results but also enables spatial mapping. This latter point could be important in castings having significant cross-section or shape changes. This spatial knowledge may also help designing and manufacturing castings for specific applications as well as understanding the physical mechanisms of variations in the microstructure.

In conclusion, drastic variations were found in number of nodules per unit area, size of graphite nodules as well as nodularity values in the examined ADI specimen. The presented scanning approach improves the representativeness and statistical reliability of the nodularity analysis. This approach also provides spatial variation of the microstructure. It should also be noted that the presented methods are not limited to ADI; they can be used to evaluate other nodular, gray and vermicular cast iron types as well.

\section{References:}

[1] Cast Metals Development Ltd., Materials \& Design 13 (1992), p.285.

[2] Putatunda etal, Mat. Sci. Eng. A 435-436 (2006), p. 112.

[3] Y.J. Kim etal, Materials Letters 62 (2008), p.357.

[4] ASTM E2567-13a Standard Test Method for Determining Nodularity and Nodule Count In Ductile Iron, ASTM International, West Conshocken, PA, 2013, www.astm.org

[5] M. Haycock, M.Sc. Thesis, Michigan Technological University (2011), MI, USA.

[6] Rashidi and Idris, Mat. Sci. Eng. A 597 (2014), p. 395.

a)

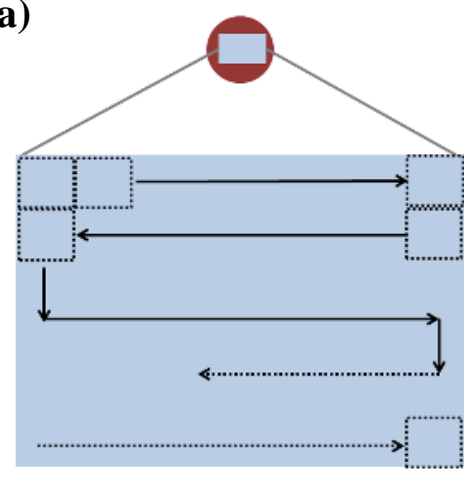

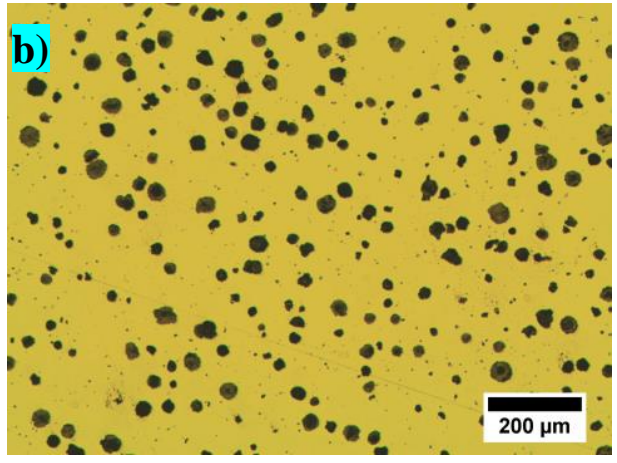

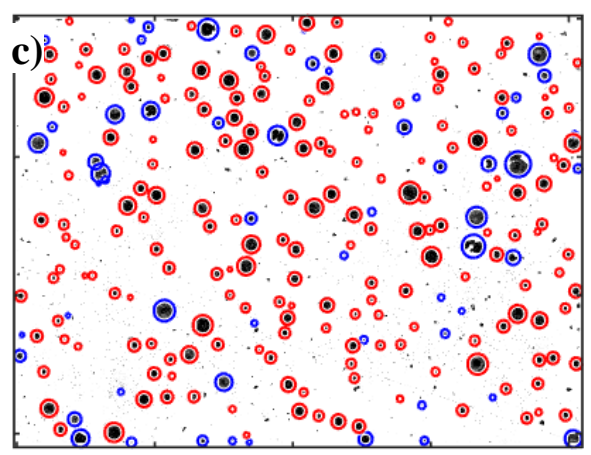

Figure 1. Raster scan pattern (a) to obtain optical micrographs (b) from the surface of the as-polished ADI specimen. (c) the micrograph analyzed by the MatLab script to identify the size and nodularity of graphite particles in accordance with the ASTM E2567. Black circles indicate nodular graphite particles, blue circles indicate graphite particles whose shape factor is not high enough to be classified as nodular.
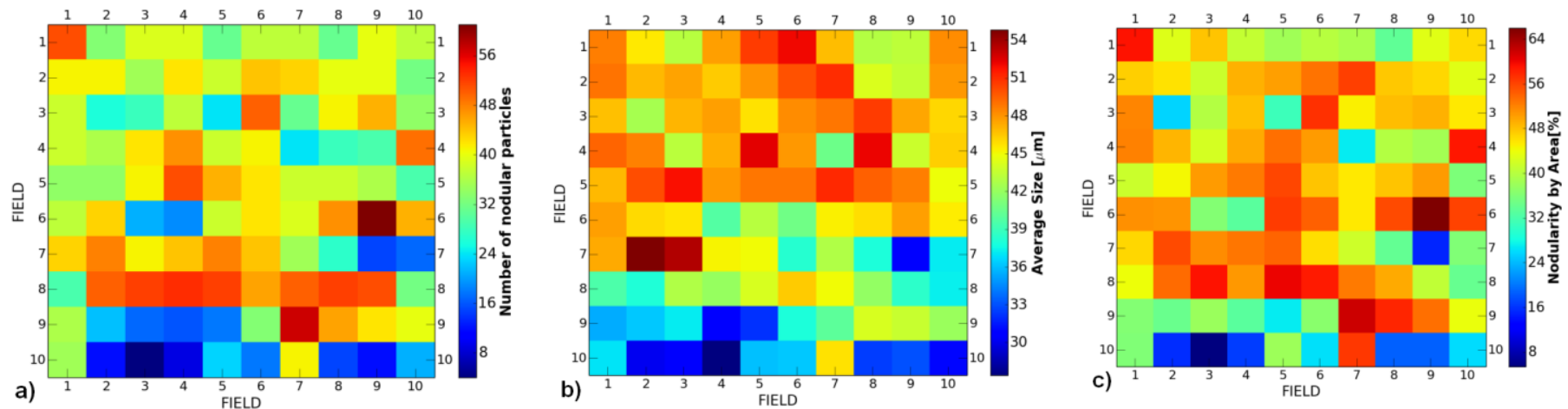

Figure 2. Maps of a) number of nodular graphite particles per field, b) average size of graphice particles and c) nodularity by area (percent) values. 